vol.6. No.1 2019

\title{
ASSESSMENT OF CARE KNOWLEDGE AND PRACTICES AMONGNURSES FOR HYPERTENSION PREGNANT WOMAN WITH GESTATIONAL Riham Gamal Kandil ${ }^{1}$, Amina Saad Gonied ${ }^{2}$, and Sabah LotfyMohamed $^{3}$
}

${ }^{1}$ A Specialized Researcher at the Obstetrics and Gynecological-nursing department, Zagazig University, Egyp

${ }^{2}$ Professor of Obstetrics and Gynecological nursing, faculty of nursing, Zagazig University, Egypt

${ }^{3}$ Assistant Professorof Obstetrics and Gynecological nursing, faculty of nursing, Zagazig University, Egypt

\section{Abstract}

Background: Gestational hypertension is one of the most common disorders seen in human pregnancies.Aim:to assess the care provided for pregnant women with gestational hypertension during labor. Methods: A descriptive cross-sectional study was conducted on 300 women with gestational hypertension and 120 nurse in the labor ward of the obstetrics department at Zagazig University Hospital. Tools: A structured interview schedule, observational checklist and labor outcomes sheet. Results: The current study showed that the majority of nurses had adequate knowledge and more than half of them had adequate scores regarding care provided for women with gestational hypertension during labor.Conclusion: The present study concluded that, higher percentage of nurses had adequate knowledge regarding the care provided for women with gestational hypertension. Additionally, more than half of them had inadequate practices regarding care provided for women with gestational hypertension during labor. Regarding labor outcomes, nearly threequarters of women were delivered vaginally and two-thirds of neonate did not admit to neonatal intensive care unit with adequate nursing care. Recommendations: developing standardized care guidelines for intrapartum nursing care for women with gestational hypertension.

Key words: gestational hypertension, care provided, maternal and neonatal outcomes.

\section{Introduction:}

Gestational hypertension $(\mathrm{GH})$ is defined as a new rise in blood pressure (BP) $\geq 140 / 90 \mathrm{~mm} \mathrm{Hg}$, presenting at or after 20 weeks gestation without significant proteinuria or other features of preeclampsia which usually resolves within 6-12 weeks of delivery (Umegbolu E I et al.,2016). According to ACOG, 2012 the prevalence of gestational hypertension and preeclampsia in the US range from $2 \%$ to $12 \%$. Healthy nulliparous women may experience higher rates of gestational hypertension $(6 \%$ to $17 \%$ ) compared with multiparous women ( $2 \%$ to $4 \%$ ). African-American women may be at greater risk than white women. Worldwide, $10 \%$ of all pregnancies are complicated by hypertension, with preeclampsia and eclampsia being the major causes of maternal and perinatalmorbidity and mortality(Shiozaki A etal. 2017).

The midwife's role in the assessment and diagnosing hypertension is fundamental to the early detection and subsequent referral that will allow treatment to be implemented rapidly, potentially minimizing the severity of the condition. The midwife is in a prime position to identify those women who are more likely to develop gestational hypertension, and respond to detection of problems (Tranquilli et al., 2016). According to (NICE,2010) Women with hypertension should have normal Intrapartum nursing care in line with Intrapartum care: management and delivery of care to women in labour in conjunction with special recommendations 
in the following areas of care, frequency of blood pressure observations during labour

,haematological and biochemical monitoring , care during epidural analgesia and mangement of second and third stage of labor.

I. Significance of the Study.

Worldwide hypertension in pregnancy have been identified as a major health problem, associated with increased perinatal morbidity and mortality. Various authors have found the frequency of hypertensive disorders of pregnancy between 7-10\%. Among them gestational hypertension was 46\%. (Hassan M et al., 2015). Pre-eclampsia (PE) complicates 2$5 \%$ of all pregnancies and gestational hypertension (GH) affects $5-10 \%$ of pregnancies.In Egypt gestational hypertension is considered a major cause of maternal death associated with $27 \%$ of direct obstetric death and $22 \%$ of all maternal deaths (Mohamed A etal.

,2013). Optimizing health care to prevent and treat women with hypertensive disorders is a necessary step towards achieving the millennium development goals (WHO, 2011). No previous study done in Zagazig City, so this study was done to assess the nursing care provided for pregnant women with gestational hypertension during labor.

\section{Aim Of The Study}

The study was aimed to assess nursing care are provided for pregnant women with gestational hypertension during labor IV. Research questions.

1. What is the availability of care provided for women with gestational hypertension during labor?

2. What is the effect of this care on maternal and neonatal out come?

\section{Material and Methods \\ Design:}

A Descriptive and cross-sectionalstudy design was used in the study

\section{Setting:}

The current study was carried out in the labor room of the obstetric department of Zagazig University Hospital

Sampling:

Type: A purposive sample.

Size :Various community based studies carried out in the pregnancy hypertensive disorders showed that HDP affect about 10-22\% of pregnancies(Donovan $\boldsymbol{P}$, 2012). The total number of the study sample was be determined according equation. The formula used for sample size calculation was;

1. $\mathrm{N}=4 \mathrm{pq} / \mathrm{d}^{2}=$

2. $\mathrm{P}=$ prevalence rate of $\mathrm{RTI}=20 \%$

3. $\mathrm{q}=100-\mathrm{p}=100-20=80 \%$

4. $\mathrm{D}=$ absolute error $=5 \%$

$\mathrm{N}=4 \mathrm{pq} / \mathrm{d}^{2}=4 * 0.2 * .8 /(.05)^{2} \approx 300$

The sample size of this study came out to be 300 women who have gestational hypertension and undergoing labor, and 120 nurses who work in the labor ward.

\section{Inclusion criteria:}

All pregnant women who attended to the labor word in the maternity department of zagazig university hospital between 25 45 years old and who have gestational hypertension during labor.

\section{Exclusion criteria:}

All pregnant women who had hypertension associated with any medical disorders such as, heart disease, kidney disease or any other medical disorder.

\section{Tools of Data Collection}

Data collection was done through the use of the following tools:

A. An interview questionnaire sheet : It was developed by the researcher in order to collect the following data:

- Part (I): Socio-demographic characteristics of the studied nurses: such as age, educational level, job status and work experience

- Part (II). Nurses knowledge about gestational hypertension: such asthe meaning, risk factors, symptoms and 


\begin{tabular}{l}
\hline \hline complications of gestational \\
hypertension \\
- Part (III). Nurse's knowledge \\
about pre and intrapartum care of \\
women with gestational \\
hypertension undergoing labor: It \\
involved knowledge about drugs for \\
management of gestational \\
hypertension.
\end{tabular}

- Part (IV). Socio-demographic characteristics of women: such as age, level of education, working status and socioeconomic level.

- Part (V). Obstetric history of women: such as gravidity and parity.

- Part (VI). Evaluation of Blood Pressure. Women mean of blood pressure.

B. Observational checklist: It was used to assess nursing care provided for women having gestational hypertension during labor. It included data about admission nursing care, nursing practice on admission for women, nursing practices during labor, and adequacy of equipment and supplies.

C. Summary labor sheet :It included two parts

- Part (I). Maternal outcome regarding nursing care provided: Mode of delivery, women satisfaction regarding nursing care services and interpersonal nursing skills.

- Part (II). Neonatal outcome regarding nursing care provided: It involved data about immediate neonatal admission to NICU, neonatal Apgar score at $1^{\text {st }}$ and $5^{\text {th }}$ minutes (e.g., normal: 7-10, mild-moderate: 4-6, sever asphyxia: 0-3) and body measurement.

Tool validity.

The content validity of tools was achieved by a panel of three professors in obstetrics and gynecology nursing who revised the tool for clarity, relevance, applicability, comprehensiveness, understanding and ease for implementation. Modifications were applied according to their opinions.

Pilot Study:

A pilot study was carried on $10 \%$ of women (30 women having gestational hypertension and who were excluded from the sample)to test the validity and reliability of the tools of data collections and estimate the time needed, the feasibility of the study and acceptance to be involved in the study. Necessary modifications were undertaken

Ethical consideration:

A verbal agreement was obtained from all the subjects prior to participation in the study, women had the right to withdraw from the study at any time and there was no harm for hypertensive pregnant women. Permission was taken from the hospital authority to conduct the study in the hospital. Secrecy and confidentiality were maintained.

\section{Fieldwork:}

Data collected through a period of six months from the first of February 2015 to the end of July 2015. Three days/week from 10 am to $4 \mathrm{pm}$ were allowed to collect pertinent data. After obtaining women's acceptance to participate in the study, the researcher started to collect data through interviewing, assessment and evaluation.

\section{Data Analysis}

Data collected throughout history, questionnaire and examination outcome measures coded, entered and analyzed using Microsoft Excel software. Data were then imported into Statistical Package for the Social Sciences (SPSS version 20.0) (Statistical Package for the Social Sciences) software for analysis. According to the type of data qualitative represent as number and percentage, quantitative continues group represent by 
mean $\pm \mathrm{SD}$, the following tests were used to test differences for significance; Differences between frequencies (qualitative variables) and percentages in groups were compared by Chi-square test. Differences between parametric quantitative independent groups by t test. $P$ value was set at $<0.05$ for significant results $\&<0.001$ for high significant result. Data were collected and submitted to statistical analysis. The following statistical tests and parameters were used.

\section{1- Mean}

$$
\bar{x}=\sum x / \mathbf{n} \sum x \text { Is the sum of }
$$

the variables.

$$
x^{2}=\sum \frac{(O-E)^{2}}{E} \text { Where: } \quad \text { : } \quad \text { The }
$$

observed value. E: The expected value.

3- The $t$ statistic to test whether the means are different can be calculated as follows:

$$
t=\frac{\bar{X}_{1}-\bar{X}_{2}}{S_{X_{1} X_{2}} \cdot \sqrt{\frac{2}{n}}}
$$

\section{Results}

Table (1): shows that nearly two third of the studied nurses were between 31-40 year. As regard level of education, $75 \%$ of the studied nurses had secondary education. Concerning job status, $76.7 \%$ of them were nurses. Wherever, more than half $(53.3 \%)$ of the nurses had working experience from 6 to 10 years.

Figure (1): illuminates that highly percentage $(89.0 \%)$ of the studied nurses had adequate knowledge regarding care provided for women with gestational hypertension during delivery. From the same figure,only11\% of them had inadequate knowledge.

Figure (3): illustrates that, more than half $(57.3 \%)$ of the studied nurses had adequate scores regarding care provided for women with gestational hypertension during delivery. However, less than half $(42.7 \%)$ of them had an inadequate score.

Figure (4):illuminates that, the most common (87\%) of the studied nurses mentioned equipment and supplies were adequate. While, $13.0 \%$ of them noticed equipment and supplies were inadequate.

Table (3): summarizes the relationship between adequate nursing care given and mode of delivery. It was observed that just about seventy-five percent $(72.2 \%)$ of women who were born vaginally, also the half $(50.2 \%)$ of them were delivered by cesarean gotten adequate nursing care. Additionally, $27.8 \%$ and $49.8 \%$ of them were delivered by vaginal and cesarean section, respectively did not receive adequate nursing care. There is a highly significant difference between mode of delivery and adequacy of nursing care provided $(\mathrm{P}=$ $0.00)$.

Table (4): Concerning the relationship between admittance of neonates into neonatal intensive care unit and adequacy of nursing care provided. Approximately, two-thirds $(61.1 \%)$ of neonates had sufficient nursing care didn't undergo to the neonatal intensive care unit. However, less half $(43.9 \%)$ of them did undergo to the neonatal intensive care unit with poor nursing care provided. There is a statistically significant difference between neonate intensive care unit admission and adequacy of nursing care $(\mathrm{p}=0.01)$.

\section{Discussion}

The social situation directly points to the quality of healthcare that these women receive, and, particularly, to nursing practice, considering that these are the healthcare professionals most involved in the providing healthcare to pregnant women with hypertension, both at the primary healthcare level, as well as to hospital inpatients (Martins et al., 2012). With regard to socio-demographic characteristics of the studied nurses, the current results found that, about two-thirds 
ASSESSMENT OF CARE KNOWLEDGE AND PRACTICES etc...

of them at the study setting were at the age group of 31 to 40 years; three-quarters of them had a secondary nursing education degree and were nurses. These results are consistent with a quantitative correlation research design was done by Jiji et al. (2016) who were found the most of the healthcare workers belong to the age group of 31 to 40 years. Similarly, Khamis (2009) demonstrated that $86.6 \%$ of the study sample had diplom in nursing.

As to years of working experience related to the study sample, the most proportion of them was observed between 6 and 10 years. Agrees with Ahmad et al., (2013) who found that near to three quarter of the nurses had more than 5 years of experience. Ethelwynn\& Nompumelelo (2016) found that majority of participants had more than 3 years of experience, which included participants with more than 10 years of experience in clinical midwifery practice. These results were incompatible with Jiji et al. (2016) who stated that majority had work experience between 2 to 5 years. The increase years of working experience may enhance the competence of health caregivers and performance-related expectations. These results suggest the need for increasing the number of practice years to provide standard nursing care and help to be modernized with new methods.

The results of this study pointed out that, the most of the nurses had correctly answered about the meaning, previous history as a risk factor and symptoms of gestational hypertension as well as complications. These findings accordance with Munirathnamma et al., (2013) who indicated that staff nurses having more knowledge toward definitions, risk factors and clinical manifestations of gestational hypertension. This result is contradictory to the study done by Stellenberg\&Ngwekazi, (2016) who were found the gap in the knowledge of nurses regarding hypertensive disorders during pregnancy was identified, only

fifty-six percent of participant answered the questions on the clinical manifestations, Whereas, twenty-eight percent had no information.

With regards to knowledge of nursing caregivers about the controlling drugs on gestational hypertension, the approximately all of them knew nifedipine and methyldopa as drugs used to control raised blood pressure. Further, all of them given an accurate answer about magnesium sulphate as a drug to control and prevent gestational hypertension. Comparable conclusions with Maembe(2012) and Jiji et al. (2014) stated that almost all health workers knew methyldopa is the drug used to control raised blood pressure. To control and prevent eclampsia, $95 \%$ of healthcare workers given magnesium sulphate. This indicates antihypertensive drugs are available at the hospital. Moreover, magnesium sulphate is very important in saving lives of these patients. Besides, fear of magnesium sulphate toxicity not widely where there are adequate devices for monitoring. The present finding found that the majority of the studied nurses had adequate knowledge regarding the care provided during childbirth for women having gestational hypertension. This is similar to the findings of Munirathnamma et al., (2013) who indicated that staff nurses have more knowledge on the aspects of management. The source of health-related information was found effective in improving the knowledge.

Regarding socio-demographic characteristics of women, more than threequarter of them were in the age group of 25 to 35 years. It is corroborated by evidence from previous studies, risk of gestational hypertension was less than half and about two-thirds higher in 35-39.9 and 40-44.9 years age old compared to 25-29.9 years age old mothers (Timofeev et al., 
2013). On the opposite direction, Sami et al., (2016) found that more than one third of the sample their age ranged from 20 to 25 years. This may due to the culture of delayed childbearing is spreading, might contribute to rising in the future incidence of gestational hypertension. Hypertension of pregnancy with increasing maternal age is due to signs of aging such as low nitric oxide levels and high oxidative stress adversely affecting relaxation of endothelium (Taddei et al., 2006).

Concerning the educational level and working status, less than half and more than two-thirds of women were secondary school and did not work, respectively. These results are supported by (silva LM et al., 2008) who indicated that low educational level is associated with a higher risk of gestational hypertension. The majority of them were of a moderate socioeconomic level. Martins, (2001) affirmed that the socioeconomic situation itself is a risk condition that also contributes to a higher incidence of gestational hypertension, as its rates are much higher in poor and developing countries. Most pregnant women have an incomplete primary or secondary education level. Almost all maternal deaths that occur in low and middle-income countries are mainly among the poorest of the poor (WHO, 2015).

Concerning an association between adequate nursing care provide for women with gestational hypertension and mode of delivery. These findings noticed that, higher proportions of women were delivered vaginally with adequate nursing care. While, less proportions of them were delivered by vaginally with inadequate nursing care. This relationship was statistically significant with $\mathrm{P}$ value of 0.0001. Similarly, Havaei (2016) who concluded that quality and safety of nursing care is dependent on multiple factors: nursing care delivery model, workload, work environment, and nursing human resource characteristics. The educational manuals based on hospital care, were specified on selected topics dealing with high-risk pregnancy.

The present findings evaluate the effect of adequacy of nursing care and newborns admitted in the intensive care unit with care services in this unit. It was revealed that, there was a statistically significant relationship between adequacy of nursing care and newborns admitted to the intensive care unit $(\mathrm{P}=0.01)$.

Rochefort \& Clarke (2010) who pointed that higher scores on the Practice Environment Scale of the Nursing Work Index (PES-NWI) were associated with higher nurse-rated quality of care. NICU administrators and managers must consider how to provide adequate staffing to ensure that needed nursing care is provided to the most newborns.

\section{Conclusion}

The highly percent of the studied nurses had adequate knowledge and adequate scores regarding care provided for women with gestational hypertension during labor. Regarding maternal out comes, nearly three-quarters of women were delivered vaginally with adequate nursing care, while more than one-quarter of them were delivered vaginally with inadequate nursing care. More than half of women were delivered by cesarean with adequate nursing care, while more than one-quarter of them were delivered by cesarean with inadequate nursing care. Regarding neonatal outcomes, approximately two-third of neonate did not admit to neonatal intensive care unit with adequate nursing care, although, more than half of them were admitted to neonatal intensive care unit with inadequate nursing care.

\section{Recommendation}

There is a massive need for developing standardized care guidelines for intrapartum nursing care for women with 
gestational hypertension

\section{References}

1. NICE Clinical guideline(2010): Hypertension in pregnancy: the management of hypertensive disorders during pregnancy. National Institute for Health and Clinical Excellence.

2. American College of Obstetricians and Gynecologists (ACOG) (2012): Chronic hypertension in pregnancy. Practice Bulletin No.125. Obstetrics and Gynecology; 119: 396-407.

3. Tranquilli AL, Dekker G, Magee L, Roberts J, Sibai BM \& Steyn W (2014): The classification, diagnosis and management of the hypertensive disorders of pregnancy: A revised statement from the ISSHP. Pregnancy Hypertension: International Journal of Women's Cardiovascular Health; 4:97-104

4. Umegbolu E I\& Ogamba J O(2017): Incidence of gestational hypertension among pregnant women (2006-2015) in Enugu State, Southeast Nigeria: a retrospective study . International Journal of Community Medicine and Public Health. ;4(2):357-362 .

5. Shiozaki A, Tanaka $\mathbf{T}$, Ito $\mathbf{M}$, Sameshima A, Inada K, Yoneda N, Yoneda S, Satoh $S$ \& Saito $S$ (2016): prenatal risk assessment of gestational hypertension and preeclampsia using clinical information. Hypertension research in pregnancy.4: 74-87.

6. Martins M, Monticelli M,

Brüggemann $O \mathrm{M}, \boldsymbol{\&}$ Costa $\mathrm{R}$

(2012): The production of knowledge regarding gestational hypertension in the strictosensu graduate nursing studies in Brazil. Revista da Escola de Enfermagem da USP, 46(4), 802808.

7. Jiji D B, Cabading M L, \& Benjamin B A (2016): A study to assess the knowledge of risk factors about pregnancy induced hypertension and the availability of supplies among health care workers in the selected health care facilities

8. Khamis, H., (2009): Assessment of nursing management during fourth stage of labor, un published master thesis, Faculty of Nursing, Ain Shams University; 89.

9. Ahmed R, Dunford J, Mehran R, Robson S\&Kunadian V (2013): Pre-eclampsia and future cardiovascular risk among women: a review. J Am Coll Cardiol; 63(18): 1815-1822.

10. Ethelwynn LS, Nompumelelo LN (2016): Knowledge of midwives about hypertensive disorders during pregnancy in primary health care. African Journal of Primary Health Care \& Family Medicine; 8(1): 20712928. http://dx.doi.org/10.4102/phcfm.v8i1. 899

11. Munirathnamma $\mathbf{M} \quad$ \& Lakshmamma $T$ (2013): Knowledge of Staff Nurses Regarding Management of pregnancy induced hypertension(PIH). International Journal of Humanities and Social Science Invention ,11(2):8-12. Available from: www.ijhssi.org

12. Stellenberg EL\&Ngwekazi NL (2016): Knowledge of midwives about hypertensive disorders during pregnancy in primary healthcare. Afr J Prm Health Care Fam Med; 8(1), a899.

13. Maembe, L. E. (2012): Management of preeclampsia/eclampsia in Dar es Salaam public health facilities: availability of supplies and knowledge of healthcare workers (Doctoraldissertation, Muhimbili University of Health and Allied Sciences.). 
14. Timofeev J, Reddy UM, Huang CC, Driggers RW, Landy HJ, Laughon SK (2013): Obstetric complications, neonatal morbidity, and indications for cesarean delivery by maternal age. Obstet Gynecol. 2013; 122(6): 1184-95.

15. Sami S, Fikry N\& Ibrahim S(2016): Investigate Evidence Based Nursing Practices In Preeclampsia Among Pregnant Woman .IOSR Journal of Nursing and Health Science . 5(2):25-31.

16. Taddei S, Virdis A, Ghiadoni L, Versari D, Salvetti A (2006): Endothelium, aging, and hypertension. CurrHypertens Rep.;8(1): 84-9.
17. World Health Organization (2011). Evaluating the quality of care for severe pregnancy complications. The WHO near-miss approach for maternal health. http://www.who.int/reproductivehealt h/publications/monitoring/97892415 02221/en.

18. Havaei F (2016): The effect of mode of nursing care delivery and skill mix on quality and patient safety outcomes (Doctoral dissertation, University of British Columbia)

19. Rochefort CM, Clarke SP (2010): Nurses' work environments, care rationing, job outcomes, and quality of care on neonatal unit. J Adv Nurs;66(10):2213-2224.

Table (1):Percentage distribution of the studied nurses according to their characteristics.

\begin{tabular}{|l|c|c|}
\hline \multicolumn{1}{|c|}{ Nurses characteristics } & N= 120 & Percentage \\
\hline Age (Years) & 19 & 15.8 \\
\hline $20-30$ & 73 & 60.8 \\
\hline $31-40$ & 28 & 23.4 \\
\hline$>40$ & 90 & 75 \\
\hline Educational level & 5 & 4.2 \\
\hline Secondary nursing education & 25 & 20.8 \\
\hline Technical nursing education & 25 & 20.8 \\
\hline Bachelor of nursing & 3 & 2.5 \\
\hline Job status & 92 & 76.7 \\
\hline Head nurse & \multicolumn{2}{|l}{} \\
\hline Supervisor & 39 & 32.5 \\
\hline Nurses & 64 & 53.3 \\
\hline Work Experience (Years) & 17 & 14.2 \\
\hline $1-5$ & \multicolumn{2}{|l|}{} \\
\hline $6-10$ & \multicolumn{3}{|l|}{} \\
\hline$>10$ &
\end{tabular}

Figure (1): Percentage distribution of the studied nurses according to their total knowledge score 


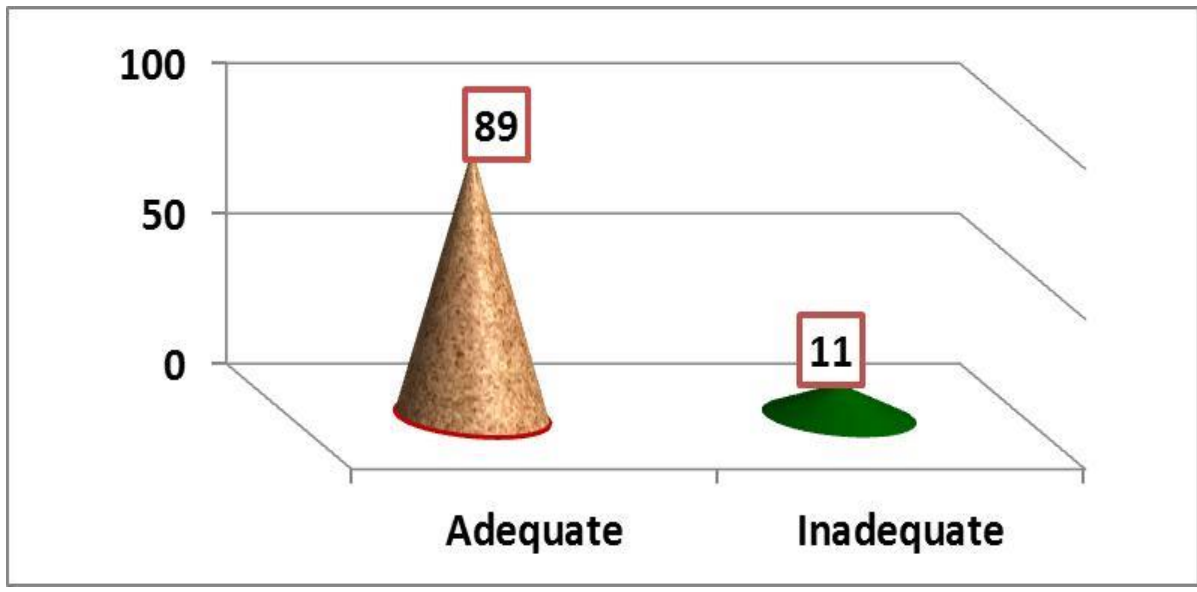

Figure (3): Percentage distribution of the studied nurses according to their total practice score

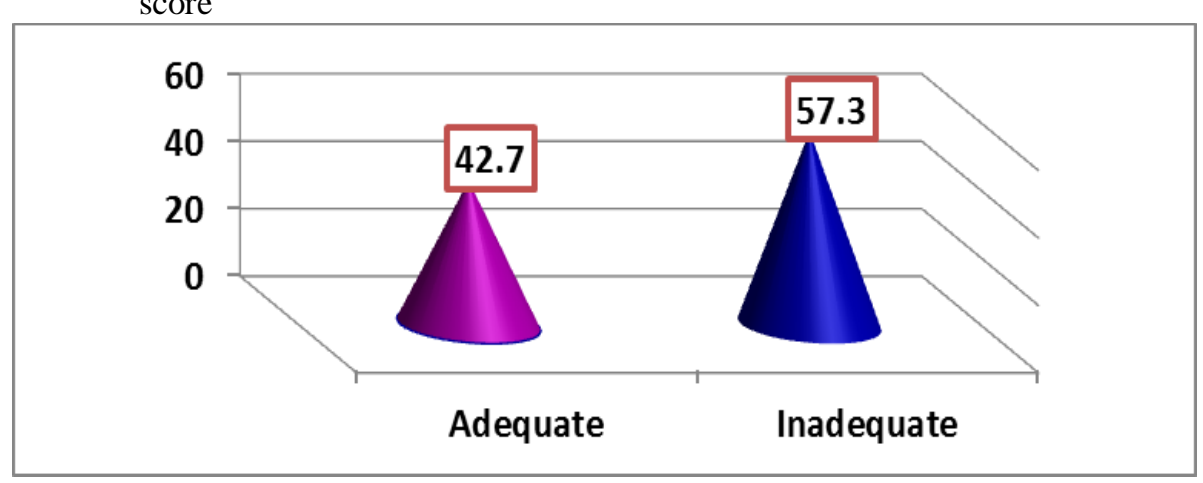

Figure (4): Distribution of the equipment and supplies according to adequacy.

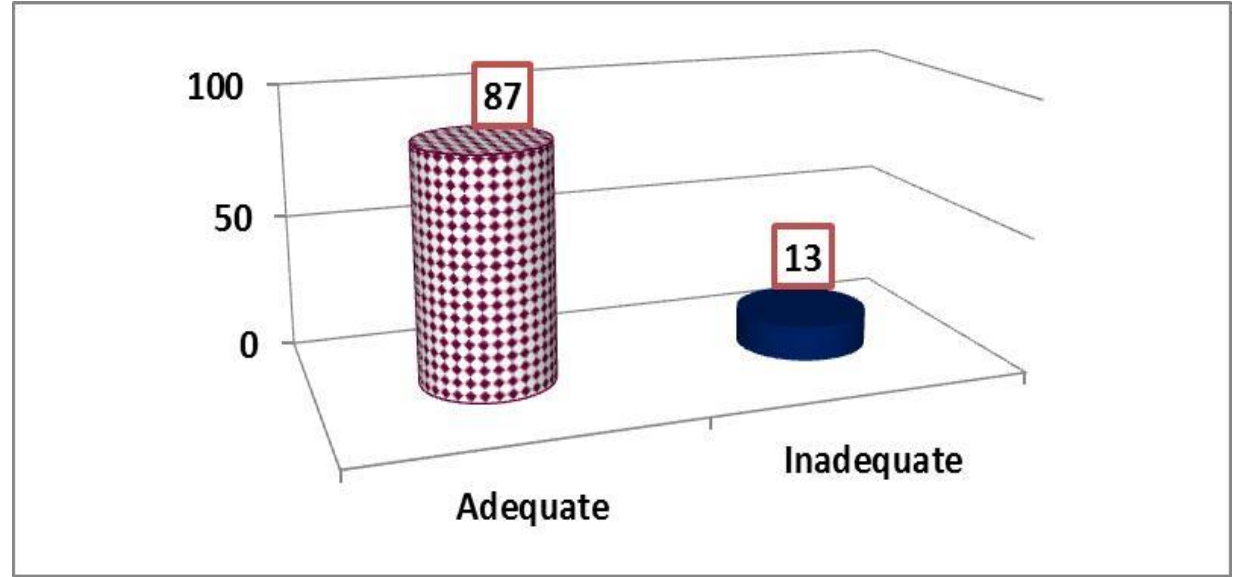


Table (2):Percentage distribution of the studied women according to their sociodemographic characteristics $(\mathrm{N}=300)$.

\begin{tabular}{|l|c|c|}
\hline \multicolumn{1}{|c|}{ Socio-demographic characteristics } & Number & Percentage \\
\hline Age (years) & 234 & 78.0 \\
\hline $25-35$ & 66 & 22.0 \\
\hline $36-45$ & 81 & 27.0 \\
\hline Level of Education & 51 & 17.0 \\
\hline Illiterate & 140 & 46.7 \\
\hline Primary school & 28 & 9.3 \\
\hline Secondary school & \multicolumn{2}{|}{} \\
\hline Higher education & 92 & 30.7 \\
\hline Working status & 208 & 69.3 \\
\hline Working & 8 & 2.7 \\
\hline Not working & 285 & 95.0 \\
\hline Socio-economic level & 7 & 2.3 \\
\hline Low & \multicolumn{3}{|l}{} \\
\hline Moderate & & \\
\hline High & \multicolumn{3}{|l|}{} \\
\hline
\end{tabular}

Table (3): Percentage distribution of women regarding mode of delivery and adequacy of nursing care provided.

\begin{tabular}{|c|c|c|c|c|c|}
\hline \multirow{2}{*}{$\begin{array}{l}\text { Mode of } \\
\text { delivery }\end{array}$} & \multicolumn{2}{|c|}{ Care provided } & \multirow[b]{2}{*}{ Total } & \multirow[b]{2}{*}{$\mathbf{X}^{2}$} & \multirow[b]{2}{*}{$\begin{array}{c}\mathbf{P} \\
\text { value }\end{array}$} \\
\hline & $\begin{array}{c}\text { Inadequate } \\
\mathbf{N}(\%)\end{array}$ & $\begin{array}{c}\text { Adequate } \\
\mathbf{N}(\%)\end{array}$ & & & \\
\hline C- delivery & $\begin{array}{c}101 \\
(49.8)\end{array}$ & $\begin{array}{c}102 \\
(50.2)\end{array}$ & $\begin{array}{c}203 \\
(100.0)\end{array}$ & \multirow[t]{2}{*}{12.8} & \multirow[t]{2}{*}{$0.00^{* *}$} \\
\hline $\begin{array}{l}\text { Vaginal } \\
\text { delivery }\end{array}$ & $\begin{array}{c}27 \\
(27.8)\end{array}$ & $\begin{array}{c}70 \\
(72.2)\end{array}$ & $\begin{array}{c}97 \\
(100.0)\end{array}$ & & \\
\hline Total & $\begin{array}{c}128 \\
(42.7)\end{array}$ & $\begin{array}{c}172 \\
(57.3)\end{array}$ & $\begin{array}{c}300 \\
(100.0)\end{array}$ & & \\
\hline
\end{tabular}

Table (4): Relationship between neonates' admittance to neonate intensive care unit and adequacy of nursing care provided

\begin{tabular}{|c|c|c|c|c|c|}
\hline \multirow{2}{*}{$\begin{array}{c}\text { NICU } \\
\text { admission }\end{array}$} & \multicolumn{2}{|c|}{$\begin{array}{c}\text { Care provided } \\
\text { Inadequate } \\
\mathbf{N}(\%)\end{array}$} & $\begin{array}{c}\text { Adequate } \\
\mathbf{N}(\boldsymbol{\%})\end{array}$ & \multirow{2}{*}{$\mathbf{X}^{\mathbf{2}}$} & $\begin{array}{c}\text { Potal } \\
\text { Value }\end{array}$ \\
\cline { 2 - 4 } & $\begin{array}{c}91 \\
(38.9)\end{array}$ & $\begin{array}{c}143 \\
(61.1)\end{array}$ & $\begin{array}{c}234 \\
(100.0)\end{array}$ & \multirow{2}{*}{6.2} & \multirow{2}{*}{$0.01^{*}$} \\
\hline No & $\begin{array}{c}37 \\
(56.1)\end{array}$ & $\begin{array}{c}29 \\
(43.9)\end{array}$ & & \\
\hline Yes & 128 & 172 & $300.0)$ & & \\
& $(42.7)$ & $(57.3)$ & $(100.0)$ & & \\
\hline Total & & &
\end{tabular}

